\title{
Magnitude of Common Mental Disorder and Factors Associated Among People Living in Addis Ababa Ethiopia 2018: Community Based Cross Sectional Study
}

Yodit Habtamu ( $\nabla$ yodita25yididya@yahoo.com )

St Amanueal Mental Specialized Hospital

Kalikidan Admasu

St Amanueal Mental Specialized Hospital

Mikiyas Tullu

St Amanueal Mental Specialized Hospital

Alem Kebede

St Amanueal Mental Specialized Hospital

\section{Research Article}

Keywords: Common mental illness, SRQ-20, Magnitude, Ethiopia

Posted Date: September 13th, 2021

DOl: https://doi.org/10.21203/rs.3.rs-863647/v1

License: (c) (i) This work is licensed under a Creative Commons Attribution 4.0 International License.

Read Full License

Version of Record: A version of this preprint was published at BMC Psychiatry on March 3rd, 2022. See the published version at https://doi.org/10.1186/s12888-022-03783-9. 


\section{Abstract}

Background: Common mental disorders are a group of distress states manifesting with anxiety, depressive and unexplained somatic symptoms, affecting individuals in different age groups, causes suffering to the individuals, families and community.

Objective: This study assessed the magnitude of Common mental disorder and associated factors among people living in Addis Ababa, Ethiopia.

Methods: Community based cross sectional study design was conducted from November 1 to 30, 2018 among people living in Addis Ababa, Ethiopia. Multistage sampling technique was used to get a total of 755 samples. Common Mental Disorder was assessed through interview using Self-Reported questionnaire (SRQ-20). The collected data were coded, entered into EPI-Info 7 and analysed by using SPPS version 20. Descriptive, analytical statistical procedure; bivariate and multivariate binary logistic regressions with odds ratios and $95 \%$ confidence interval was employed. The statistical significance was accepted at $\mathrm{p}$ value $<0.05$.

Result: In this study a total of 723 study subjects were participated, with response rate of

95.7\%.The prevalence of common mental disorders was $24.7 \%$ with [ $95 \% \mathrm{Cl} ; 21.6$ - 27.7]. Females ( $A O R=2.1 ; 95 \% \mathrm{Cl} ; 1.39-3.23)$, Divorced/widowed (AOR=2.55; 95\% Cl; 1.16- 5.59), daily labourers (AOR=2.52; 95\% Cl; 1.3- 4.88, chronic medical illness ( $\mathrm{AOR}=4.5 ; 95 \% \mathrm{Cl} ; 2.46-8.24)$. are independent predictors of CMD and educational status (primary, secondary and diploma)was positively associated with CMD. in this study. Regarding education (primary, secondary and diploma) (AOR=0.34; $95 \% \mathrm{Cl} ; 0.17$ 0.66 )and $(A O R=0.35 ; 95 \% \mathrm{Cl} ; 0.19-0.67)$ has positively associated with common mental disorders.

Conclusion: The prevalence of common mental disorders was found high. Female sex, marital status like Divorced/Widowed, daily labour workers and chronic medical illness were found to be independent predictors of CMD and educational status (primary, secondary school and diploma holders) was were found to be protective factors

\section{Introduction}

There are significant number of people in the community who are suffering from common mental disorders characterized by with the combination of mild depression, mild anxiety and medically unexplained physical symptoms which results in additional burden to the primary care settings. $(1,2)$. common mental disorder is highly prevalent which has impact at the individual, family and community level (3).

The fact that no one is immune for mental illness makes any one in every corner of the globe vulnerable to mental health problems in their life time. This fact led to the recognition that mental health condition truly has public importance $(4,5)$. According to report from WHO $25 \%$ of the world population will develop 
at least one mental illness in their life time (6). Due to high rate of relapse and related complication almost one out of ten the global burden of disease is represented by $\operatorname{CMD}(7,8)$. According to WHO unipolar disorder is the fourth leading cause of morbidity and premature death. With approximately $6 \%$ of total disability, it is projected that depression will be the leading cause of disease burden globally by year 2030 (9).It is also associated with high levels of morbidity and mortality and the most common disorder contributing to suicide $(7,10)$

In developing countries including Ethiopia there are many barriers which affect mental health care (11). Contrary to the national health policy of Ethiopia that prioritize care delivery at the community level, there is huge treatment gap among CMDs patients visiting primary health care setting. Most studies in Ethiopia in the field of mental health mainly focused on specific disorders. Furthermore, other mental problems such as common mental disorders are not well-recognized within the community. Help-seeking for common mental disorders is most often limited to the family or local community, and those who are living with these disorders usually remains undetected in general health settings, which leads to inappropriate prescribing of ineffective treatments and is a missed opportunity for suicide prevention.

Twelvemonthprevalenceestimatesofmoodandanxietyrangefrom6.6\%to18.1\%acrosssurveysfromAustralia and the US community(12).In South America like Brazil and Santiago, Chile prevalence of CMDs was reported $29.9 \%$ and $25 \%$ respectively. $(3,13)$. In Britain estimated prevalence of CMD is $24.6 \%(14)$ and in similar country with different study setting reported $24.2 \%(15)$ In the European countries such as Greece and Sweden the magnitude of common mental disorders ishighrangingfrom $14-17.2 \%$,while in eastern Asia the prevalence is around $8.8 \%(16-18)$.

In Africa, different studies revealed different CMDs prevalence results in population based surveys. Accordingly, the prevalence of CMDs in Kenya and South Africa was $10.8 \%$, and $34.9 \%$ respectively. Another study conducted in Nigeria found $12.1 \%$ of life time prevalence and $5.8 \%$ twelve-month prevalence of CMDs (19-21).

In Ethiopia in different areas community based studies conducted using the same instrument reported that prevalence of common mental disorders ranging from $11.2-33.4 \%(22-28)$.

Concerning the factors associated with common mental disorders female sex, low educational attainment, older age, unemployed, positive family history of mental illness, chronic physical health problems and substance use were found to be strong indicators of CMD in different literatures $(23,29-$ 31).

Addis Ababa is a capital city where most people from different corners of the country migrate in from time to time due partly to search for job, education and training and the massive problems related to land and agricultural productivity. According to WHO report urbanization may have deleterious consequences for mental health through the influence of increased stressors and adverse life events, such as overcrowded and polluted environments, poverty and dependence on cash economy, high levels of violence and reduced social support 
We presume highly that community will manifest common mental disorders. So this study is designed to assess Prevalence and Factors Associated with Common Mental disorders among people living in Addis Ababa, Ethiopia. Thus, the study will provide significant evidence in order to enforce policy makers and different stakeholders to integrate mental health service with primary health care system to manage common mental disorders at the community level.

\section{Objectives}

The aim of this study was to assess the magnitude of Common mental disorder and associated factors among people living in Addis Ababa, Ethiopia.

\section{Materials And Methods}

\section{Study Design, Period and Setting}

Community based Cross-sectional study was conduct from November 1 to 30 , 2018. The study was conducted in Addis Ababa which is a chartered city and the capital city of Ethiopia with an estimated population of $4,215,965$ and annual growth rate of $3.8 \%$. Almost one out of five urban dwellers in Ethiopia lives in Addis Ababa. It is located in the geographic centre of the country surrounded by hills and mountains. The capital city has an elevation of 2,355 $\mathrm{m}$ and has an estimated density of 5165.1 people per square kilo meter. The city has 10 sub cities and 99 woredas,

\section{Study Population}

All adult residing in Addis Ababa available at the time of data collection in selected house hold were the study populations.

\section{Inclusion and Exclusion criteria}

All adult living in Addis Ababa who are $\geq 18$ years of age were included whereas participants who were seriously ill, unable to communicate and homeless adults were excluded.

\section{Sample Size and Sampling}

The minimum number of sample required for this study was estimated by using Single population proportion formula considering the following assumptions: Proportion of the prevalence of common mental disorder conducted in Jima 2015 was (33.6\%) (28).; hence, $P=33.6 \%(0.336)$ was used. $Z=$ standard normal distribution $(Z=1.96)$ with confidence interval of $95 \%$ and $\nabla=0.05$., design effect $(D=2)$ then adding $10 \%$ non-respondents give a total sample size of 755 . 


\section{Sampling Technique}

Multistage sampling techniques was used and 3 sub-city were selected from 10 sub-city by simple random sampling methods followed by selection of 8 Woredas. The sample size was distributed to each Woreda according to probabilities proportional to size. Lottery sampling method was use to select house hold from Woredas, when more than one study subject were found in one household a lottery method was used to select participant. And also when selected study subject in household were unavailable, next household was interviewed.

\section{Measurements}

Structured interview administered questioner was used which has four sub sections: $1^{\text {st }}$ Sociodemographic questioner to assess background information. Common Mental Disorder was measured by using Self-Reported questionnaire (SRQ-20) which was developed by WHO, was used to assess presence of common mental disorders neurotic symptoms (anxiety, depression, somatic) was measuring using 20 items; it scored 0 or 1 . A score of 1 indicate that the presence of symptoms in the past one month and a score 0 indicates that the symptom was absents. And it can obtain by summing the score from each 20 items. Higher scores indicate probability of CMD, while lower scores indicate no CMD.A cut of point $\geq 7$ was used in this study (22). The SRQ had previously been translated into Amharic and validated in Ethiopia, and it has been used for community surveys(32).

An item on 3rd section was Clinical variable: history of chronic medical illness such as tuberculosis, HIV/AIDS, Diabetics, Cardiovascular disease, asthma, hypertension and cancers. And other clinical variable was family history of mental illness. Final section was to asses substance use such as khat, alcohols, tobacco, and cannabises.

\section{Data Collection Technique}

To assure the quality of the data high emphasis was given in designing data collection instrument for its simplicity. The questionnaire was checked for clarity, simplicity, and understandebility. The reliability test was done on the scale to assess the common mental disorders and the Cronbach's alpha was 0.84 . Data collectors were trained on an introduction to common mental disorders, research methods, interviewing skills, sampling, recruitment, and the ethical aspects of the research. Data were collected by sixteen health extension workers and regularly supervised by four senior master psychiatry professional .The collected data were reviewed and checked for completeness and relevance by supervisors and principal investigator each day (33).

\section{Data Processing and Analysis}


First the data were checked for completeness and consistency. Then it was coded and entered in to the computer using Epi Info version 3.5.1 and analysed by using SPSS version 20. Descriptive statistic was used to explain the study participants in relation to study variables. Binary logistic regression was fitted to the data. Bivariate and multivariate logistic regression analysis was conducted to identify associated factors of common mental disorders. The strength of the association was presented by odds ratio with $95 \%$ C.I and P-Value less than 0.05 was consider as statistically significant.

\section{Ethical Approval and Consent to Participate}

The researcher was obtained Ethical clearance from ethical review committee of St Amanuel Mental Specialized Hospital. A formal letter of permission was obtained from AMSH. Written informed consent was obtained from each study participants after explaining the purpose and benefit of the study. This study was conducted in accordance with the Declaration of Helsinki. This form indicated that participation is voluntary, and that client has the right to withdraw from completing the questionnaire at any time they wish without a reason. Participants also informed that there is no expectation of additional treatment or any associated benefits and risks for them participating in the study.

\section{Results}

\section{Socio- demographic characteristics}

A total of 723 study subjects were participated in this study, making a response rate of $95.7 \%$. More than half of participants(56.7\%) were females, half of them (50.8\%)married, more than onethird (35.4\%) of them was Amhara, more than half (63.2\%) of them Orthodox Christian, nearly one-third $(28.5 \%)$ of them was completed secondary school and more than one-third(37.3\%) were within the age group of 25-34 years old, more than one-fourth(25.9\%) was daily labourer and more than one-third (40.8\%) were in the income group of 100-800 ETB. (Table 1).

\section{Table 1}

Distribution of socio demographic and economic characteristics of study participants in Addis Ababa, Ethiopia, $2018(n=723)$ 


\begin{tabular}{|c|c|c|c|}
\hline \multicolumn{2}{|c|}{ Variables } & Frequency & Percentage \\
\hline \multirow[t]{4}{*}{ Age } & $18-24$ & 75 & 10.4 \\
\hline & $25-34$ & 270 & 37.3 \\
\hline & $35-44$ & 190 & 26.3 \\
\hline & $\geq 45$ & 188 & 26.0 \\
\hline \multirow[t]{2}{*}{ Sex } & Male & 313 & 43.3 \\
\hline & Female & 410 & 56.7 \\
\hline \multirow[t]{3}{*}{ Marital status } & Married & 367 & 50.8 \\
\hline & Single & 297 & 41.1 \\
\hline & Others* & 59 & 8.2 \\
\hline \multirow[t]{4}{*}{ Religion } & Orthodox & 457 & 63.2 \\
\hline & Protestant & 116 & 16.0 \\
\hline & Muslim & 128 & 17.7 \\
\hline & Others ${ }^{\star \star}$ & 22 & 3.0 \\
\hline \multirow[t]{5}{*}{ Ethnicity } & Amahara & 256 & 35.4 \\
\hline & Oromo & 186 & 25.7 \\
\hline & Tigre & 74 & 10.2 \\
\hline & Gurage & 147 & 20.3 \\
\hline & Others ${ }^{\star \star \star}$ & 60 & 8.3 \\
\hline \multirow{5}{*}{$\begin{array}{l}\text { Educational } \\
\text { status }\end{array}$} & Unable to read and write & 80 & 11.1 \\
\hline & Primary school & 131 & 18.1 \\
\hline & High school & 206 & 28.5 \\
\hline & Diploma & 187 & 25.9 \\
\hline & Degree and above & 119 & 16.5 \\
\hline \multirow{5}{*}{$\begin{array}{l}\text { Occupational } \\
\text { status }\end{array}$} & Private employed & 178 & 24.6 \\
\hline & Government employed & 172 & 23.8 \\
\hline & Daily laborer & 187 & 25.9 \\
\hline & Unemployed & 98 & 13.6 \\
\hline & 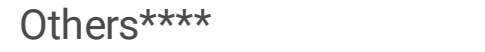 & 88 & 12.2 \\
\hline
\end{tabular}


801-1500

$1501-3000$

$>3000$
127

156

145
17.6

21.6

20.1

Note *Divorce, Widowed and Separated. ** Catholic and Jehovah witness. *** Hadiya and Welayita. $\star \star \star \star$ Pensioners and house servant .

\section{Clinical variables and substance use of respondents}

Hundreds seventy of participants (16.2\%) has chronic medical illness history and ninety-four $(15.1 \%)$ of theme had family history of mental illness. (Table2). Regarding substance use among the total study participants $160(22.1 \%)$ of them were reported history of drinking alcohol within the last three months whereas $34(4.7 \%)$ of them were using tobacco products, $54(7.5 \%)$ of them use khat and $16(2.2 \%)$ of respondent use cannabises currently. (Fig2).

Table 2

Distribution of clinical factors of study participants in Addis Ababa, Ethiopia, $2018(n=723)$

\begin{tabular}{|c|c|c|c|}
\hline Variables & & Frequency & Percentage \\
\hline \multirow[t]{2}{*}{ Previous history of mental illness } & Yes & 117 & 16.2 \\
\hline & No & 606 & 83.8 \\
\hline \multirow[t]{2}{*}{ Family history of mental illness } & Yes & 94 & 13.0 \\
\hline & No & 629 & 87 \\
\hline
\end{tabular}

\section{Prevalence of common mental disorder and distribution of symptoms}

The overall prevalence of Common Mental Disorder in this study was found to be 178 (24.7\%), with [95\% Cl; 21.6 - 27.7] among adults in Addis Ababa, Ethiopia.62.9\% of females and $37.1 \%$ of males. (Fig 1).In majority of the study participants out of the total twenty symptoms consisted in SRQ; headache, easily tired, Sleep badly, feel nervous, tens or worried and Feel tired all the time during the last 30 days were the most commonly reported symptoms (Table-3) 
Distribution of SRQ symptoms among the study participants $(n=723)$ living in Addis Ababa, Ethiopia, 2018

\begin{tabular}{|llll|}
\hline SYMPTOMES & FREQUENCY & PERCENT & 48.7 \\
\hline Headache & 352 & & 30.3 \\
\hline Easily tired & 219 & & \\
\hline Sleep badly & 217 & 30 & \\
\hline Feel nervous, tens or worried & 197 & 27.2 & 25.6 \\
\hline Feel tired all the time & 185 & & \\
\hline Poor appetite & 185 & 25.6 & \\
\hline Lost interest in things & 184 & 25.4 & \\
\hline Difficult enjoy daily activity & 155 & 21.4 & \\
\hline Thought of ending life & 155 & 21.4 & \\
\hline Poor digestion & 152 & 21 & \\
\hline Difficult in decision making in day to day activity & 149 & 20.6 & \\
\hline Feel unhappy & 140 & 19 & 18.3 \\
\hline Daily works suffering & 132 & 15.8 \\
\hline Uncomfortable feeling in the stomach & 114 & 14.5 \\
\hline Feel worthless person & 105 & 14.1 \\
\hline Unable to play a useful part in life & 102 & & \\
\hline Others & 262 & & \\
\hline
\end{tabular}

\section{Factors associated with common mental disorders}

To determine the association of independent variables on Common Mental Disorders, bivariate logistic regression analysis was carried out. Variables sex, age, marital status, educational status, occupational status, Income, chronic medical illness and family history of mental illness with P-value less than 0.2 in bivariate regression were found to be significant and included for multivariable logistic regression. In multivariable logistic regression being female, widowed/divorce in marital status, educational status (primary, secondary school and diploma holders), daily labourer workers and chronic medical illness were statistically significant with Common Mental Disorder at $p$-value $<0.05$. (Table4). 
Table 4

Bivariate and Multivariate analysis of factors associated with common mental disorders among respondents living in Addis Ababa,Ethiopia, 2018. 


\begin{tabular}{|c|c|c|c|c|c|}
\hline \multirow[t]{2}{*}{ Variables } & \multirow[t]{2}{*}{ Total (f, \%) } & \multicolumn{2}{|l|}{ CMD } & \multirow[t]{2}{*}{$\operatorname{COR}(95 \% \mathrm{Cl})$} & \multirow[t]{2}{*}{$\mathrm{AOR}(95 \% \mathrm{Cl})$} \\
\hline & & NO & YES & & \\
\hline \multicolumn{6}{|l|}{ Sex } \\
\hline Female & $410(56.7 \%)$ & $\begin{array}{l}298 \\
(54.7 \%)\end{array}$ & $112(62.9 \%)$ & $\begin{array}{l}1.41(0.99- \\
1.99)\end{array}$ & $\begin{array}{l}2.1(1.39- \\
3.23)^{\star \star \star}\end{array}$ \\
\hline Male & $313(43.3 \%)$ & $247(45.3 \%)$ & $66(37.1 \%)$ & 1 & 1 \\
\hline \multicolumn{6}{|l|}{ Age } \\
\hline $18-24$ & $75(10.4 \%)$ & $54(9.9 \%)$ & $21(11.8 \%)$ & 1 & 1 \\
\hline $25-34$ & $270(37.3 \%)$ & $229(42 \%)$ & $41(23 \%)$ & $\begin{array}{l}0.46(0.25- \\
084)\end{array}$ & $\begin{array}{l}0.56(0.28- \\
1.12)\end{array}$ \\
\hline $35-44$ & $190(26.3 \%)$ & $142(26.1 \%)$ & $48(27 \%)$ & $\begin{array}{l}0.87(0.48- \\
1.58)\end{array}$ & $\begin{array}{l}1.19(0.57- \\
2.46)\end{array}$ \\
\hline$>45$ & $188(26 \%)$ & $120(22 \%)$ & $68(38.2 \%)$ & $\begin{array}{l}1.45(0.81- \\
2.61)\end{array}$ & $\begin{array}{l}2.03(0.92- \\
4.48)\end{array}$ \\
\hline \multicolumn{6}{|l|}{ Marital status } \\
\hline Single & $297(41.1 \%)$ & $227(41.7 \%)$ & $70(39.3 \%)$ & 1 & 1 \\
\hline Married & $367(50.8 \%)$ & $286(52.5 \%)$ & $81(45.5 \%)$ & $\begin{array}{l}0.92(0.64- \\
1.32)\end{array}$ & $\begin{array}{l}1.12(0.66- \\
1.88)\end{array}$ \\
\hline Divorced/widowed & $59(8.2 \%)$ & $32(5.9 \%)$ & $27(15.2 \%)$ & $\begin{array}{l}2.7(1.54- \\
4.88)^{\star \star}\end{array}$ & $\begin{array}{l}2.55(1.16- \\
5.59)^{\star}\end{array}$ \\
\hline \multicolumn{6}{|l|}{ Educational status } \\
\hline $\begin{array}{l}\text { Unable to read and } \\
\text { write }\end{array}$ & $80(11.1 \%)$ & $48(8.8 \%)$ & $32(18 \%)$ & $\begin{array}{l}1.67(0.92- \\
3.03)\end{array}$ & $\begin{array}{l}0.49(0.2- \\
1.21)\end{array}$ \\
\hline Primary school & $131(18.1 \%)$ & $89(16.3 \%)$ & $42(23.6 \%)$ & $\begin{array}{l}1.18(0.69- \\
2.03)\end{array}$ & $\begin{array}{l}0.39(0.18- \\
0.83)^{\star}\end{array}$ \\
\hline High school & $206(28.5 \%)$ & $164(30.1 \%)$ & $42(23.6 \%)$ & $\begin{array}{l}0.64(0.38- \\
1.08)\end{array}$ & $\begin{array}{l}0.34(0.17- \\
0.66)^{\star \star}\end{array}$ \\
\hline Diploma & $187(25.9 \%)$ & $159(29.2 \%)$ & $28(15.7 \%)$ & $\begin{array}{l}0.44(0.25- \\
0.78)^{\star \star}\end{array}$ & $\begin{array}{l}0.35(0.19- \\
0.67)^{\star \star}\end{array}$ \\
\hline Degree and above & $119(16.5 \%)$ & $85(15.6 \%)$ & $34(19.1 \%)$ & 1 & 1 \\
\hline \multicolumn{6}{|l|}{ Occupational status } \\
\hline $\begin{array}{l}\text { Government } \\
\text { employed }\end{array}$ & 172(23.8) & $145(26 \%)$ & $27(15.2 \%)$ & 1 & 1 \\
\hline Private employed & $178(24.6 \%)$ & $135(24.8 \%)$ & $43(24.2 \%)$ & 1.71(1.0- & $1.76(0.92-$ \\
\hline
\end{tabular}




\begin{tabular}{|c|c|c|c|c|c|}
\hline & & & & $2.92)^{\star}$ & $3.35)$ \\
\hline Daily laborer & $187(25.9 \%)$ & $127(23.3 \%)$ & 60(33.7\%) & $\begin{array}{l}2.54(1.52- \\
4.24)^{\star \star \star}\end{array}$ & $\begin{array}{l}2.52(1.3- \\
4.88)^{\star \star}\end{array}$ \\
\hline Unemployed & $98(13.6 \%))$ & $74(13.6 \%)$ & $24(13.5 \%)$ & $\begin{array}{l}1.74(0.94- \\
3.23)\end{array}$ & $\begin{array}{l}1.35(0.6- \\
3.01)\end{array}$ \\
\hline Others $s^{\star \star \star \star}$ & $88(12.2 \%)$ & $64(11.7 \%)$ & $24(13.5 \%)$ & $\begin{array}{l}2.01(1.07- \\
3.76)^{\star}\end{array}$ & $\begin{array}{l}0.45(0.24- \\
0.83)\end{array}$ \\
\hline Gross family monthly & & & & 1 & 1 \\
\hline \multicolumn{6}{|l|}{ Income(ETB) } \\
\hline $100-800$ & $295(40.8 \%)$ & $202(37.1 \%)$ & $93(52.2 \%)$ & 1 & 1 \\
\hline $801-1500$ & $127(17.6 \%)$ & $103(18.9 \%)$ & $24(13.5 \%)$ & $\begin{array}{l}0.51(0.31- \\
0.84)^{\star}\end{array}$ & $\begin{array}{l}0.84(0.46- \\
1.55)\end{array}$ \\
\hline $1501-3000$ & $156(21.6 \%)$ & $119(21.8 \%)$ & $37(20.8 \%)$ & $\begin{array}{l}0.67(0.43- \\
1.05)\end{array}$ & $\begin{array}{l}1.31(0.72- \\
2.39)\end{array}$ \\
\hline$>3000$ & $145(20.1 \%)$ & $121(22.2 \%)$ & $24(13.5 \%)$ & $\begin{array}{l}0.43(0.26- \\
0.71)^{\star \star}\end{array}$ & $\begin{array}{l}0.58(0.29- \\
1.16)\end{array}$ \\
\hline \multicolumn{6}{|l|}{$\begin{array}{l}\text { Chronic medical } \\
\text { illnes }\end{array}$} \\
\hline Yes & $117(16.2 \%)$ & $69(12.7 \%)$ & $48(27 \%)$ & $\begin{array}{l}2.55(1.68- \\
3.86)^{\star \star \star}\end{array}$ & $\begin{array}{l}4.5(2.46- \\
8.24)^{\star \star \star}\end{array}$ \\
\hline No & $606(83.8 \%)$ & $476(87.3 \%)$ & $130(73 \%)$ & 1 & 1 \\
\hline \multicolumn{6}{|l|}{ Family hx of Mi } \\
\hline Yes & $94(13 \%)$ & $78(14.3 \%)$ & $16(9 \%)$ & $\begin{array}{l}0.59(0.33- \\
1.04)\end{array}$ & $\begin{array}{l}0.45(0.24- \\
0.83)\end{array}$ \\
\hline No & $629(87 \%)$ & $467(85.7 \%)$ & 162(91\%) & 1 & 1 \\
\hline
\end{tabular}

Females were 2.1 time more likely to develop Common mental disorder than males ( $\mathrm{AOR}=2.1 ; 95 \% \mathrm{Cl}$; 1.39- 3.23). Those who Divorced/Widowed in marital status were 2.55 time more likely to develop Common mental disorder than single(AOR $=2.55 ; 95 \% \mathrm{Cl} ; 1.16-5.59)$. Daily labourer were 2.52 time more likely to develop Common mental disorder than governmental employee (AOR=2.52; $95 \% \mathrm{Cl}$; 1.3- 4.88). And also those who has history of chronic medical illness 4.5 times more likely to develop Common mental disorder than those who hasn't history of chronic medical illness (AOR=4.5; 95\% Cl; 2.46- 8.24).

Regarding educational status the odds of developing Common mental disorder who finished primary school , secondary school and diploma holders were decreased by $61 \%, 66 \%$ and $65 \%$ compared to degree holder (AOR=0.39; 95\% Cl; 0.18-0.83), (AOR=0.34; 95\% Cl; 0.17-0.66)and(AOR=0.35; 95\% Cl; 0.19-0.67) respectively. 


\section{Discussion}

The finding from the current study showed that estimated prevalence of Common mental disorder was $24.7 \%$ it was in line with studies done in Britain at different study settings $24.6 \%$ and $24.2 \%(14,15)$ and study done Illibabure was reported $27.2 \%(27)$ possible reason might be the nature of illness and same instrument used.

This study was found to be higher from studies done in Europe like Greece's ,Sweden ranges from 14$17.2 \%$ and eastern Asia was $8.8 \%(16-18)$. The difference could be cultural difference and socioeconomic and in Keneya10.8\%, (19) and Nigeria 5.8\% (21) the reason could be the tool (CIS-R,CIDI). And in Ethiopia, Butajira (17\%), Harar (14.9\%), Hadiy a(11.2\%) and in Addis Ababa $(11.7 \%) .(22,23,25)$ and The higher prevalence might be those studies done within the past two decades, through this period of time there have been a considerable changes in the nature of modern urbanization and socio-cultural status of the community. This deference might be due to cut off point of the tool SRQ-20 varied.

This study was found to be lower from studies done in South Africa (34.9\%) (20) and study in Ethiopia such as Kombolich32.4\% and Jima $33.4 \%(26,28)$ and this deference might be due to cut off point of the tool SRQ-20 varied and explained by population difference.

Regarding independent predictors of Common mental disorder were female, widowed/divorce in marital status, daily labour workers and chronic medical illness were found to be independent predictors of CMD and also educational status (primary, secondary school and diploma holders) are positively associated with CMD.

Females were 2.1 time more likely to develop Common mental disorder than males. this findings supported by different studies like in Ethiopia, Greece, and South Africa((17, 20, 23, 27)) possible reason could be females are deprived of schooling and receive burden of social and household responsibility than males and also they are highly vulnerable for physical and sexual abuse. In addition to this low socio-economic status of females might have predispose them to higher risk for common mental disorders. On the other hand hormonal difference may also play important role.

Divorced/widowed in marital status were 2.55 time more likely to develop Common mental disorder than single this finding supported by study conducted in, Santiago,Chiiy.(13). the possible reason could be household responsibilities, supporting family financially falling to one person which is biggest challenge and it may predispose them to emotional and physical strain.

Daily labourer was 2.52 time more likely to develop Common mental disorder than governmental employee the possible reason could be there monthly income is insufficient and not secured for not lose job can lead to stressful and unsafe situation, which might trigger CMDs. Based on different theories low income can be also explained in part of poverty, people experiencing poverty face difficulties to fulfil basic needs, it interfered with their ability to participate in productive activity, contribute to significant stigma and hampered their abilities to build and sustain social relationships 
Regarding educational status the odds of developing Common mental disorder who finished primary school, secondary school and diploma holders were decreased by $61 \%, 66 \%$ and $65 \%$ compared to degree holder the possible reason could be having formal education increase access to the most professional jobs, decrease vulnerability and insecurity and enhance social capital.(34) WHO (1994) A user's guide to the Self Reporting Questionnaire (SRQ).Geneva.

Those who has history of chronic medical illness 4.5 times more likely to develop Common mental disorder than those who hasn't history of chronic medical illness. This finding is in line with study done in Kenya, Taiwan and Brazil $(3,16,19)[23,20,3]$ respectively Those who are living with chronic physical illness might have limited daily activity, experience dissatisfaction in life which may expose them for depression and anxiety; therefore, it might have increased the risk of acquiring CMDs..

\section{Limitation of the Study}

This study has restraint because of design: cross sectional has prevented us from reporting the casual relationship of the associations we found and social desirability bias might affect.

\section{Conclusion And Recommendations}

The prevalence of common mental disorders was found high. Female sex, marital status like Divorced/widowed, daily labour workers and chronic medical illness were found to be independent predictors of CMD and educational status (primary, secondary school and diploma holders) was found to be protective factors. Its recommendable to consider mental health focused screening carried out in regular interval by trained Health extension workers and linkage with mental health service specially for females and those who are divorced and also special attention should be given for those who have chronic physical illness.

\section{Abbreviations}

CMD, WHO, CISD,SRQ-20, AOR, COR, SPSS-20

\section{Declarations}

\section{Ethical approval and consent to participants}

Ethical clearance was obtained from St Amanueal Mental Specialized hospital Ethical Review Committee (ERC). A formal letter of permission was obtained from AMSH. Written informed consent was obtained from each study participants after explaining the purpose and benefit of the study. This study was conducted in accordance with the Declaration of Helsinki.. This form indicated that participation is voluntary, and that client has the right to withdraw from completing the questionnaire at 
any time they wish without a reason. Participants also were informed that there is no expectation of additional treatment or any associated benefits and risks for them participating in the study.

\section{Consent for publication:}

Not applicable

\section{Data Sharing Statement}

All data included in manuscript has been included in the form of tables. the non identified raw data generated and/or analyzed during the current study are not publicly available due to confidentiality issues but are available from the corresponding author on reasonable request through email address of yodita25yididya@yahoo.com.

\section{Competing interests:}

None.

\section{Funding:}

This study was partially funded by St Amanueal Mental Specialized Hospital. It covers secretor expenditure, data collectors fee, temple developments and data entry costs. Data analysis, interpretation, data reports writings and manuscript development were covered by all authors. and there is no funding available for this publication.

\section{Contributors:}

$\mathrm{YH}, \mathrm{KA}, \mathrm{MT}$ and AK designed the study. Performed the analysis and interpretation of data and drafted the paper. All authors: prepared the draft manuscript, read and approved the final manuscript.

\section{Acknowledgments}

The Authors would like to acknowledge St Amanueal Mental Specialized Hospital and Addis Ababa City Administration and Sub cities for their timely administrative supports to complete this study. And also like to thanks to all study participants, data collectors and supervisors.

\section{References}


1. Goldberg DP, Huxley P. Common mental disorders: a bio-social model: Tavistock/Routledge; 1992.

2. Lazarus R, Freeman M. Primary-level mental health care for common mental disorder in resourcepoor settings: models \& practice. A literature review Pretoria: Medical Research Council. 2009.

3. Saulo V, Maura M, Tania M, Jair S. prevalence of common mental disorders in residents of urban areas of Feira de Santana. BA, Brazil. 2010;13(4):1-11.

4. Desjarlais RR. World mental health: Problems and priorities in low-income countries: Oxford University Press, USA; 1995.

5. Lopez AD, Mathers CD, Ezzati M, Jamison DT, Murray CJ. Measuring the global burden of disease and risk factors, 1990-2001. Global burden of disease and risk factors. 2006;1:1-14.

6. Theodoridou A, Rössler W, Preedy V, Watson R. Disease burden and disability-adjusted life years due to schizophrenia and psychotic disorders. 2010.

7. Patel V. Mental health in low-and middle-income countries. British medical bulletin. 2007;81(1):8196.

8. McCarthy KL, Carter PE, Grenyer BF. Challenges to getting evidence into practice: expert clinician perspectives on psychotherapy for personality disorders. Journal of Mental Health. 2013;22(6):48291.

9. Eaton WW, Martins SS, Nestadt G, Bienvenu OJ, Clarke D, Alexandre P. The burden of mental disorders. Epidemiologic reviews. 2008;30(1):1-14.

10. Peltzer K, Naidoo P, Matseke G, Louw J, Mchunu G, Tutshana B. Prevalence of psychological distress and associated factors in tuberculosis patients in public primary care clinics in South Africa. BMC psychiatry. 2012;12(1):1-9.

11. Health WHODoM, Abuse S, Organization WH, Health WHODoM, Health SAM, Evidence WHOMH, et al. Mental health atlas 2005: World Health Organization; 2005.

12. Baumeister $H$, Härter $M$. Prevalence of mental disorders based on general population surveys. Social psychiatry and psychiatric epidemiology. 2007;42(7):537-46.

13. Araya R, Rojas G, Fritsch R, Acuña J, Lewis G. Common mental disorders in Santiago, Chile: prevalence and socio-demographic correlates. The British Journal of Psychiatry. 2001;178(3):22833.

14. Weich S, Lewis G, Jenkins SP. Income inequality and the prevalence of common mental disorders in Britain. The British Journal of Psychiatry. 2001;178(3):222-7.

15. Hatch SL, Frissa S, Verdecchia M, Stewart R, Fear NT, Reichenberg A, et al. Identifying sociodemographic and socioeconomic determinants of health inequalities in a diverse London community: the South East London Community Health (SELCoH) study. BMC public health. 2011;11(1):1-17.

16. Skapinakis P, Bellos S, Koupidis S, Grammatikopoulos I, Theodorakis PN, Mavreas V. Prevalence and sociodemographic associations of common mental disorders in a nationally representative sample of the general population of Greece. BMC psychiatry. 2013;13(1):1-14. 
17. Johansson R, Carlbring P, Heedman $\AA$, Paxling B, Andersson G. Depression, anxiety and their comorbidity in the Swedish general population: point prevalence and the effect on health-related quality of life. PeerJ. 2013;1:e98.

18. Kawakami N, Takeshima T, Ono Y, Uda H, Hata Y, Nakane Y, et al. Twelve-month prevalence, severity, and treatment of common mental disorders in communities in Japan: preliminary finding from the World Mental Health Japan Survey 2002-2003. Psychiatry and clinical neurosciences. 2005;59(4):441-52.

19. Jenkins R, Njenga F, Okonji M, Kigamwa P, Baraza M, Ayuyo J, et al. Prevalence of common mental disorders in a rural district of Kenya, and socio-demographic risk factors. International journal of environmental research and public health. 2012;9(5):1810-9.

20. Havenaar JM, Geerlings MI, Vivian L, Collinson M, Robertson B. Common mental health problems in historically disadvantaged urban and rural communities in South Africa: prevalence and risk factors. Social Psychiatry and Psychiatric Epidemiology. 2008;43(3):209-15.

21. Gureje O, Lasebikan VO, Kola L, Makanjuola VA. Lifetime and 12-month prevalence of mental disorders in the Nigerian Survey of Mental Health and Well-Being. The British Journal of Psychiatry. 2006;188(5):465-71.

22. Kebede D, Alem A, Rashid E. The prevalence and socio-demographic correlates of mental distress in Addis Ababa, Ethiopia. Acta psychiatrica scandinavica. 1999;100:5-10.

23. Alem A, Kebede D, Woldesemiat G, Jacobsson L, Kullgren G. The prevalence and socio-demographic correlates of mental distress in Butajira, Ethiopia. Acta psychiatrica scandinavica. 1999;100:48-55.

24. Tafari S, Aboud FE, Larson CP. Determinants of mental illness in a rural Ethiopian adult population. Social science \& medicine. 1991;32(2):197-201.

25. Hunduma G, Girma M, Digaffe T, Weldegebreal F, Tola A. Prevalence and determinants of common mental illness among adult residents of Harari Regional State, Eastern Ethiopia. Pan African Medical Journal. 2017;28(1).

26. Yimam K, Kebede Y, Azale T. Prevalence of common mental disorders and associated factors among adults in Kombolcha Town, Northeast Ethiopia. J Depress Anxiety S. 2014;1:2167-1044.

27. Engidaw NA, Abdu Z, Chinani I. Prevalence and associated factors of common mental disorders among residents of Illu Ababore zone, southwest Ethiopia: a cross-sectional study. International Journal of Mental Health Systems. 2020;14(1):1-8.

28. Kerebih H, Soboka M. Prevalence of common mental disorders and associated factors among residents of Jimma town, South West Ethiopia. Population. 2016;8:6-8.

29. Shidhaye R, Patel V. Association of socio-economic, gender and health factors with common mental disorders in women: a population-based study of 5703 married rural women in India. International journal of epidemiology. 2010;39(6):1510-21.

30. Jenkins R, Mbatia J, Singleton N, White B. Common mental disorders and risk factors in urban Tanzania. International journal of environmental research and public health. 2010;7(6):2543-58. 
31. Alem A, Jacobsson L, Hanlon C. Community-based mental health care in Africa: mental health workers' views. World Psychiatry. 2008;7(1):54.

32. Hanlon C, Medhin G, Alem A, Araya M, Abdulahi A, Hughes M, et al. Detecting perinatal common mental disorders in Ethiopia: validation of the self-reporting questionnaire and Edinburgh Postnatal Depression Scale. Journal of affective disorders. 2008;108(3):251-62.

33. Ejigu AK, Seraj ZR, Gebrelibanos MW, Jilcha TF, Bezabih YH. Depression, anxiety and associated factors among housemaids working in Addis Ababa Ethiopia. BMC psychiatry. 2020;20(1):1-11.

34. Beusenberg M, Orley JH, Organization WH. A User's guide to the self reporting questionnaire (SRQ. World Health Organization; 1994.

\section{Figures}

\section{Prevalence of CMD}

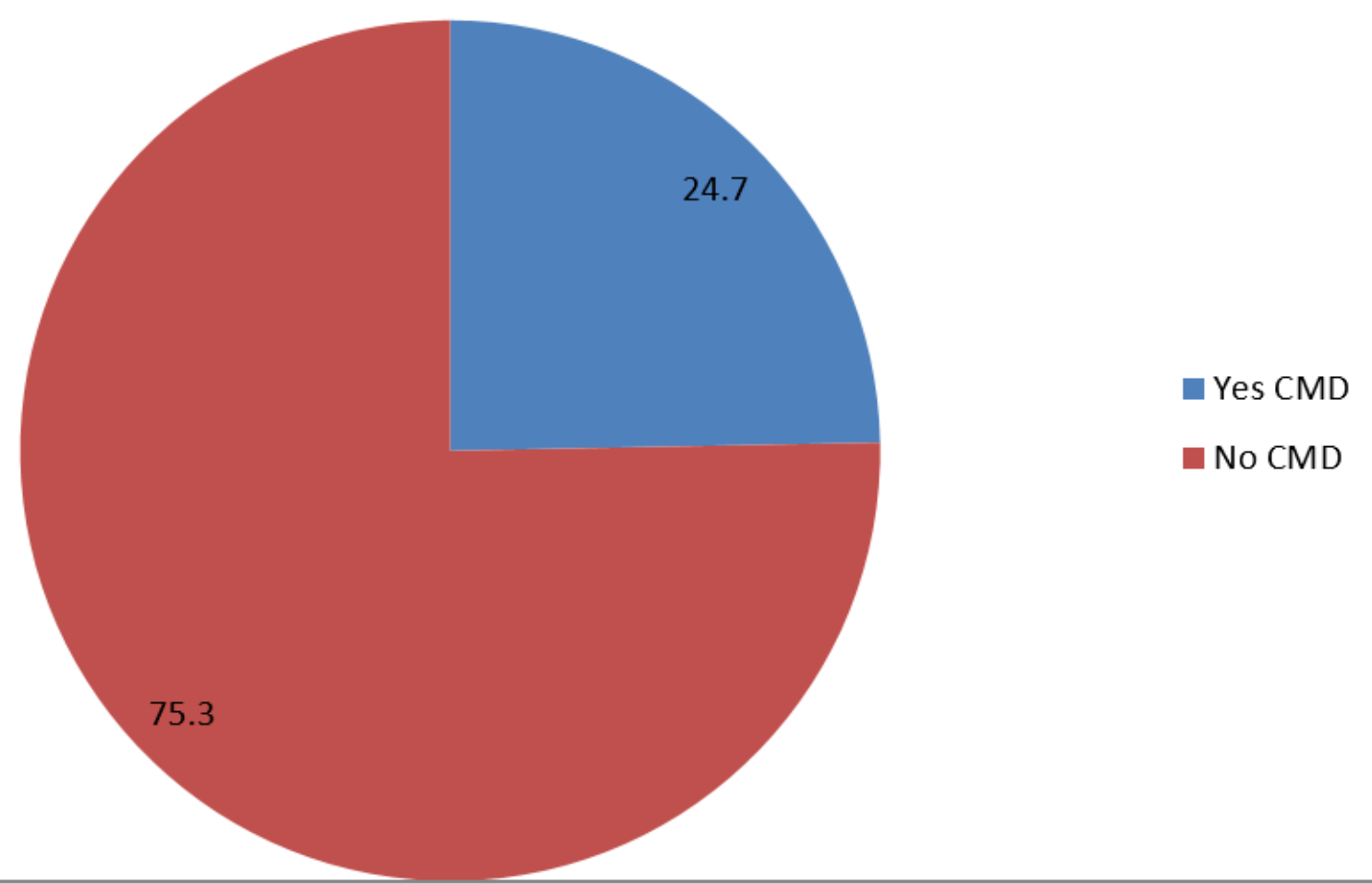

Figure 1

Prevalence of Common Mental Disorder among living in Addis Ababa, Ethiopia, 2018 


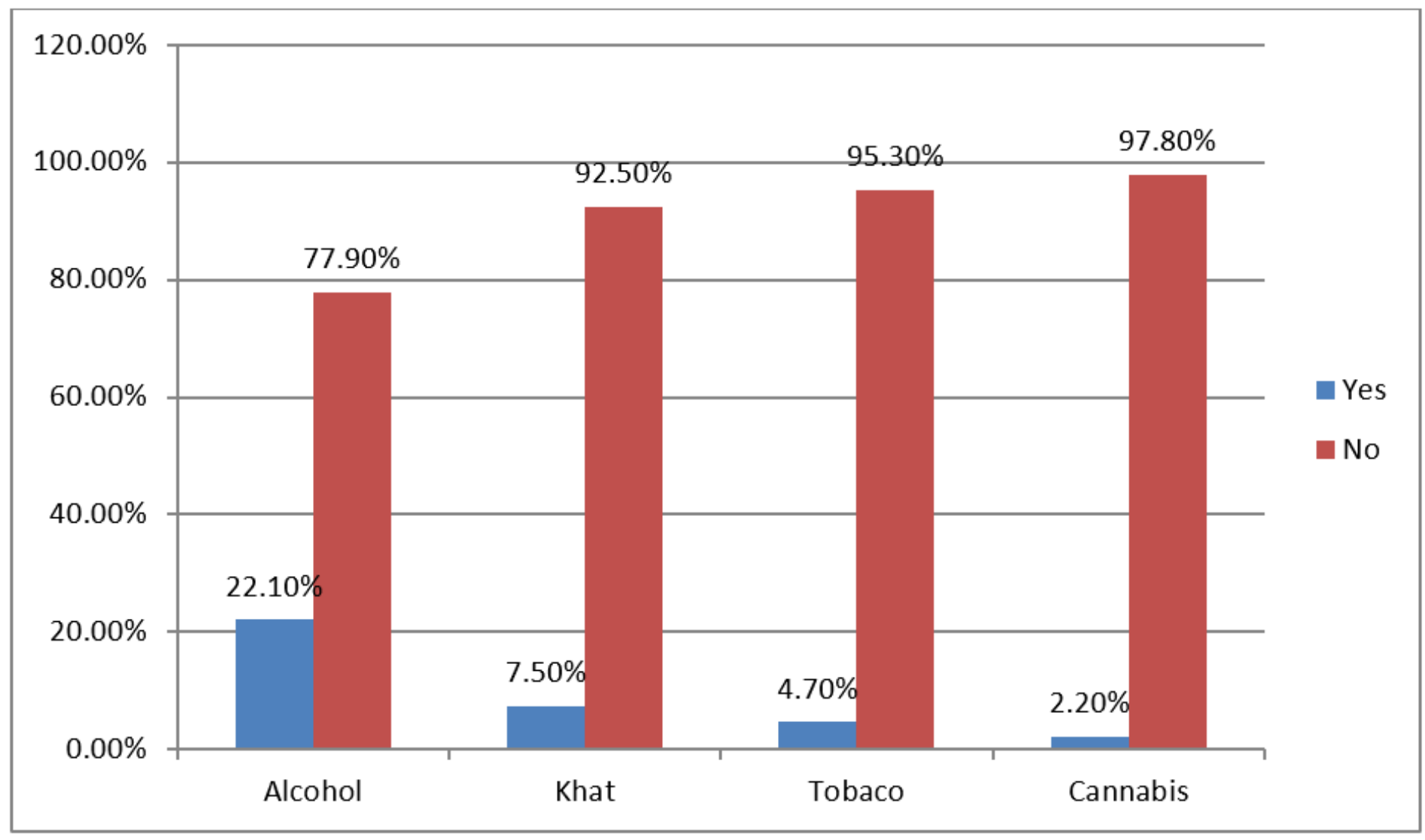

Figure 2

Distribution of substance use of study participants in Addis Ababa, Ethiopia, 2018 ( $n=723)$.

\section{Supplementary Files}

This is a list of supplementary files associated with this preprint. Click to download.

- suplementarydata.docx 